\title{
Enhancement and inhibition effects on the corneal permeability of timolol maleate: polymers, cyclodextrins and chelating agents
}

Article

Accepted Version

Creative Commons: Attribution-Noncommercial-No Derivative Works 4.0

Rodríguez, I., Vázquez, J. A., Pastrana, L. and Khutoryanskiy, V. V. (2017) Enhancement and inhibition effects on the corneal permeability of timolol maleate: polymers, cyclodextrins and chelating agents. International Journal of Pharmaceutics, 529 (1-2). pp. 168-177. ISSN 0378-5173 doi:

https://doi.org/10.1016/j.ijpharm.2017.06.075 Available at https://centaur.reading.ac.uk/71721/

It is advisable to refer to the publisher's version if you intend to cite from the work. See Guidance on citing.

Published version at: http://www.sciencedirect.com/science/article/pii/S0378517317305835

To link to this article DOI: http://dx.doi.org/10.1016/j.ijpharm.2017.06.075

Publisher: Elsevier

All outputs in CentAUR are protected by Intellectual Property Rights law, including copyright law. Copyright and IPR is retained by the creators or other copyright holders. Terms and conditions for use of this material are defined in the End User Agreement. 


\section{www.reading.ac.uk/centaur}

\section{CentAUR}

Central Archive at the University of Reading

Reading's research outputs online 


\title{
Enhancement and inhibition effects on the corneal
}

\author{
permeability of timolol maleate: Polymers,
}

\section{cyclodextrins and chelating agents}

Isabel Rodriguez ${ }^{1,2}$, José Antonio Vázquez ${ }^{3}$, Lorenzo Pastrana ${ }^{4}$ and Vitaliy V. Khutoryanskiy ${ }^{1 *}$

${ }^{1}$ University of Reading, School of Pharmacy, Whiteknights, PO box 224, Reading, RG66AD, United Kingdom, e-mail: v.khutoryanskiy@,reading.ac.uk

${ }^{2}$ University of Vigo, Analytical and Food Chemistry Department, Ourense, Spain

${ }^{3}$ Marine Research Institute (IIM-CSIC), Group of Recycling and Valorization of Waste Materials (REVAL), Vigo, Spain

${ }^{4}$ International Iberian Nanotechnology Laboratory (INL), Braga, Portugal

Keywords

Hyaluronic acid; chitosan; timolol; bioavailability; glaucoma; mucoadhesion

\section{Abstract}

This study investigates how both bioadhesive polymers (chitosan, hyaluronic acid and alginate) and permeability enhancers (ethylene glycol- bis(2-aminoethylether)- N, N, N', N'- tetraacetic acid (EGTA) and hydroxypropyl-ß-cyclodextrin) influence the permeability of the anti-glaucoma drug timolol maleate through ex vivo bovine corneas. Our results showed that only the permeability enhancers alone were able to increase drug permeability, whereas the polymers significantly reduced drug permeation, and however, they increased the pre-corneal residence of timolol. Ternary systems (polymer-enhancer-drug) showed a reduced drug permeability compared to the polymers alone. Fluorescence microscopy analysis of the epithelium surface confirmed there was no evidence of epithelial disruption caused by these formulations, suggesting that polymer-enhancer interactions 
reduce drug solubilization and counteract the disruptive effect of the permeability enhancers on the surface of the cornea. Further mucoadhesive tests, revealed a stable interaction of chitosan and hyaluronic acid with the epithelium, while alginate showed poor mucoadhesive properties. The differences in mucoadhesion correlated with the permeability of timolol maleate observed, i.e. formulations containing mucoadhesive polymers showed lower drug permeabilities.

The results of the present study indicate polymers acting as an additional barrier towards drug permeability which is even more evident in the presence of permeability enhancers like EGTA and hydroxypropyl-ß-cyclodextrin. Then, this study highlights the need to adequately select additives intended for ocular applications since interactions between them can have opposite results to what expected in terms of drug permeability.

\section{Introduction}

The topical application of drugs is the most popular and well-accepted route of administration for the treatment of various eye conditions (Ludwig, 2005). However, the bioavailability of ophthalmic drugs is very poor due to the effective protective mechanisms of the eye (Lee and Robinson, 1986), including blinking, lachrymation, and drainage (Ludwig, 2005). Therefore, frequent instillations of eye drops or high drug concentrations are needed to achieve therapeutic levels in the tissues (Andrés-Guerrero et al., 2011), which might induce toxic side effects and cellular damage at the ocular surface (Baudouin, 1996). In addition, the treatment of certain ocular diseases such as glaucoma follows the administration of combinations of two or more drugs (Bell et al., 2010), and therapies must be continued throughout the lifetime of the patient (Andrés-Guerrero, 2011), leading to a lack of patient's compliance. Glaucoma is the leading cause of irreversible blindness throughout the world and the lowering of intraocular pressure (IOP) at present is the only therapeutic approach proven to be successful (Lorenz and Pfeiffer, 2014). For many years now, ß-adrenergic receptor blocking agents (ß-blockers) have been the first choice for the treatment of ocular hypertension and primary open-angle glaucoma (Lorenz and Pfeiffer, 2014). Timolol maleate is a nonselective $\beta$ - 
blocker (Brooks and Gillies, 1992) used alone or more frequently, in combination with other medicaments (García-López, 2014).

Although in general, timolol is well tolerated by patients (Brooks and Gillies, 1992), approximately $80 \%$ of topically administered eye drops is reported to drain through the nasolacrimal duct and is systemically absorbed (Shell, 1982). Therefore it is necessary to deepen research into new mechanisms focused on increasing the bioavailability of timolol at the ocular surface. In this regard, the use of bioadhesive polymers has been proposed as components of antiglaucoma formulations to reduce ocular toxicity, improve drug efficacy, and protect the ocular surface in long-term therapies (Andrés-Guerrero, 2011). Both the ability to increase the formulation viscosity (Saettone et al., 1982) and the bioadhesive properties (Kaur and Smitha, 2002) of polymers were reported to reduce the drainage after instillation and therefore, increase the therapeutic efficacy of the ophthalmic drugs. The most common biopolymers used in the formulation of ocular solutions include natural, synthetic and semi-synthetic high molecular weight molecules (Kaur and Smitha, 2002), which are capable of forming strong noncovalent bonds with the mucin coating biological membranes (Almeida et al., 2014). Some examples of mucoadhesive polymers for ocular application are derivatives of cellulose (methylcellulose, carboxymethylcellulose, hydroxypropylcellulose, and hydroxyethylcellulose), polyvinyl alcohol (PVA), polyacrylic acid (PAA), chitosan, and hyaluronic acid. Nevertheless the biodegradability, biocompatibility and non-toxicity of the natural biopolymers, mainly glycosaminoglycans, make them excellent candidates for the development of drug delivery devices.

Besides extending the residence time of the drug it is necessary to promote the permeability through the cornea using penetration enhancers or absorption promoters (Kaur and Smitha, 2002), in order to improve drug bioavailability. These compounds include some preservatives such as benzalkonium chloride and cetylpyridinium chloride that were reported to enhance penetration of some active compounds due to the disruption of the hydrophobic barrier of the corneal epithelium (Andrés-Guerrero, 2011). Surfactants, calcium chelators and cyclodextrins are among other 
penetration enhancers commonly used in ocular formulations. Surfactants are incorporated into the lipid bilayer of the epithelium, resulting in the formation of mixed micelles that cause the removal of phospholipids and hence lead to membrane solubilization (Kaur and Smitha, 2002). Surfactants can also increase the paracellular transport of drugs by affecting the tight junctions between epithelial cells (Deli, 2009). In the same way, calcium chelators disrupt the corneal epithelium by extracting $\mathrm{Ca}^{2+}$ ions (Kaur and Smitha, 2002) which are responsible for the maintenance of the effectiveness of the epithelium barrier. The polyaminocarboxylic acids ethylenediaminetetraacetic acid (EDTA) and its analogue ethylene glycol- bis(2-aminoethylether)- N, N, N', N'- tetraacetic acid (EGTA) have ion sequestering properties. Both calcium chelators were reported to reduce the electrical resistance of corneal membranes, confirming their ability to modify the barrier function, and to increase the corneal permeability of riboflavin in vitro (Morrison and Khutoryanskiy, 2014). Finally, cyclodextrins are oligosaccharides with a lipophilic central cavity and hydrophilic outer surface which are used as excipients in ocular formulations because of their ability to increase the water solubility of hydrophobic drugs (Loftsson and Stefánsson, 2002), such as riboflavin (Morrison et al., 2013). These authors proposed cyclodextrins are responsible for the extraction of cholesterol and other lipids from ocular cellular membrane being the reason for the observed increase in riboflavin permeability (Morrison et al., 2013).

In the present study, we investigated the effect of different formulations containing biopolymers (hyaluronic acid, chitosan and alginate) and permeability enhancers (calcium chelators and cyclodextrins) on timolol maleate permeability through bovine cornea. We also analysed whether these formulations modified the corneal integrity and how their mucoadhesive properties affected the permeability of timolol. For a better comparison of results between treatments, we developed mathematical models to accurately quantify the apparent permeability of the drug and retention of the polymers on the corneal surface.

\section{Materials and methods}




\subsection{Materials}

Timolol maleate was kindly supplied by Fine Chemicals Ltd (Dorset, United Kingdom). Triethylamine hydrochloride was purchased from Fluka. Chitosan medium molecular weight (190,000-310,000 Da, 75-85\% deacetylation), sodium alginate medium viscosity $(12,000-40,000$ Da), fluorescein isothiocyanate-dextran (FITC-dextran) 70,000 Da, N-(3-dimethylaminopropyl)-N'ethylcarbodiimide hydrochloride (EDC) and phosphoric acid were purchased from Sigma-Aldrich (Gillingham, United Kingdom). Hydroxypropyl- $\beta$-cyclodextrin (HP-ß-CD), and ethylene glycolbis(2-aminoethylether)- N,N,N',N' -tetraacetic acid (EGTA) were obtained from TCI Ltd (Oxford, United Kingdom). Hyaluronic acid was obtained by fermentation of Streptococcus zoeepidemicus ATCC 35246 (Amado et al., 2016), followed by acid hydrolysis using $\mathrm{H}_{3} \mathrm{PO}_{4}$ to a final $\mathrm{MW}$ of 24,000 Da. Sodium chloride, potassium chloride, sodium phosphate, potassium dihydrogen phosphate, sodium hydroxide, Minisart syringe filters $(0.2 \mu \mathrm{m})$, optimal cutting temperature compound (OCT) and methanol were obtained from Fisher Scientific (Hemel Hempstead, United Kingdom). Vectashield mounting medium with 4',6-diamidino-2-phenyl- indole (DAPI) was obtained from Vector Laboratories Ltd. (Peterborough, United Kingdom).

\subsection{HPLC analysis}

HPLC analysis was conducted using a PerkinElmer series 200 HPLC system comprising of 785 A UV-vis detector, series 200 quaternary pump and series 200 autosampler (PerkinElmer Inc., UK), Ascentis $\mathrm{C}_{18}$ column, $150 \mathrm{~mm} \times 4.6 \mathrm{~mm}, 5 \mu \mathrm{m}$ (part number: $581324-\mathrm{U}$ ) and data acquisition software (Peaksimple, version 4.09, SRI Inc., USA). Analysis of timolol maleate was achieved with a run time of 5 min using the method adapted from (El-Kamel, 2002). The mobile phase consisted of a mixture of methanol and triethylamine hydrochloride (45:55) under isocratic conditions, a flow rate was used at $1 \mathrm{~mL} \min ^{-1}$ at $30^{\circ} \mathrm{C}$ and detected with a $\mathrm{UV}$ detector $(295 \mathrm{~nm})$. The retention time of timolol maleate was $2.85 \mathrm{~min}$ and the detection limit was $0.1 \mu \mathrm{M}$. Quantification of timolol 
maleate concentration in the samples was achieved by linear interpolation in a calibration curve of timolol maleate standards at concentrations ranging from 0.28 to $2.8 \mu \mathrm{g} \mathrm{mL}^{-1}$.

\subsection{Preparation of animal tissues}

Bovine eyes were provided by PC Turners abattoirs (Farnborough, United Kingdom) and stored on ice during transport. The eyes were carefully handled and used whole or cornea dissected depending on the experiment. The corneas were dissected using a sharp blade with $2-3 \mathrm{~mm}$ of sclera attached, rinsed with PBS, and wrapped in a cling film to prevent dehydration. Fresh tissues were stored at $4^{\circ} \mathrm{C}$ in a refrigerator and used within $48 \mathrm{~h}$ prior to experiments, preserved according to previous ocular drug permeability tests (Morrison et al., 2013; Morrison and Khutoryanskiy, 2014).

Corneal sections from experiments were prepared by setting the cornea segment in OCT, quick freezing on dry ice, and subsequent microtome sectioning. Specimens were prepared for microscopy using a microtome (Bright, model 5040) within a cryostat (Bright, model OTF). Sections were cut at $7 \mu \mathrm{m}$, placed in groups of four on $75 \mathrm{~mm} \times 25 \mathrm{~mm}$ glass slides, and dried gently using a hot air blower for $10 \mathrm{~min}$ from a distance of around $50 \mathrm{~cm}$. The specimens were stained using Vectashield with DAPI mounting medium and a glass coverslip placed over the specimens. All cornea sections were examined within $48 \mathrm{~h}$ of preparation using an AXIOCAM MRm1.3 MP digital camera attached to a Zeiss AXIO Imager A1 fluorescent microscope, using AXIO Vs 40 V.4.8.2.0 software (Zeiss, Oberkochen, Germany). A $10 \times$ magnification eyepiece together with a $5 \times$ magnification objective lens was employed, and a light filter for DAPI fluorescence was selected.

\subsection{Transepithelial electric resistance (TEER)}

Formulations (Table 1) ability to modify the corneal barrier was assessed by TEER measurements which were carried out using adapted low volume $(5 \mathrm{~mL}$ each side) Ussing chambers with an EVOM2 Epithelial Voltohmmeter and STX2 electrode (World Precision Instruments, Inc., USA) as reported in Morrison and Khutoryanskiy (2014). After an initial measurement ( $\left.t_{0}\right)$, resistance values 
were recorded at $30 \mathrm{~min}$ intervals for $2 \mathrm{~h}$ and TEER values were calculated using the following equation:

$$
T E E R=R \times A
$$

where $\mathrm{R}$ is the resistance in $k \Omega$, and $A$ is the area of the membrane in $\mathrm{cm}^{2}$. For better data comparison, TEER values were normalized (0-1) by dividing the resistance values at each time by the initial measurement of each series, which was recorded with corneal membrane just after the formulation was pipetted into the anterior chamber.

\subsection{Corneal permeability}

Table 1. Composition of the formulations containing chitosan $(\mathrm{CH})$, alginate $(\mathrm{AL})$, hyaluronic acid (HA), hydroxypropyl- $\beta$-cyclodextrin (HP-ß-CD), and glycol-bis(2-aminoethylether)- N, N, N', N' tetraacetic acid (EGTA) tested in this study.

\begin{tabular}{cccc}
\hline Formulation & $\begin{array}{c}{[\text { Timolol] }} \\
\left(\mathrm{mg} \mathrm{mL}^{-1}\right)\end{array}$ & $\begin{array}{c}\text { [Polymer] } \\
\left(\mathrm{mg} \mathrm{mL}^{-1}\right)\end{array}$ & $\begin{array}{c}\text { [Additive] } \\
\left(\mathrm{mg} \mathrm{mL}^{-1}\right)\end{array}$ \\
\hline Control & 5 & & - \\
CH & 5 & 1 & - \\
AL & 5 & 1 & - \\
HA & 5 & 1 & - \\
HP-B-CD & 5 & - & 30 \\
EGTA & 5 & - & 1 \\
HA+HP-B-CD & 5 & 1 & 30 \\
AL+HP-B-CD & 5 & 1 & 30 \\
CH+HP-B-CD & 5 & 1 & 30 \\
HA+EGTA & 5 & 1 & 1 \\
AL+EGTA & 5 & 1 & 1 \\
CH+EGTA & 5 & 1 & 1 \\
\hline
\end{tabular}

The effect of different formulations (Table 1) on corneal permeability of timolol maleate was studied in vitro using Franz diffusion cells. Polymer solutions $\left(1 \mathrm{mg} \mathrm{mL}^{-1}\right)$ of sodium hyaluronate, chitosan and sodium alginate were prepared in PBS and tested alone or in combination with EGTA (5 mg mL $\left.\mathrm{mL}^{-1}\right)$ or HPß-CD (30 mg mL $\mathrm{mL}^{-1}$, Table 1). To prepare chitosan solutions in PBS, the 
commercial polymer was completely dissolved in the minimal volume $(\sim 1 \mathrm{~mL})$ of acetic acid $0.1 \mathrm{M}$ and then made up to the appropriate volume with PBS. Timolol was added at a concentration of 5 $\mathrm{mg} \mathrm{mL} \mathrm{m}^{-1}$. Bovine corneas were mounted between donor and receiver compartments of standard Franz diffusion cells, epithelium side facing uppermost. The receiver compartment was filled with PBS (16.5 mL), ensuring no air bubbles were trapped under the membrane. Experiments were conducted in a water bath and stirred at $37 \pm 1^{\circ} \mathrm{C}$ to mimic physiological temperature at the corneal surface. One millilitre of the corresponding formulation containing timolol maleate was added to the donor compartment and then sealed with a cling film to prevent dehydration. Samples $(0.3 \mathrm{~mL})$ were taken every $30 \mathrm{~min}$ for $240 \mathrm{~min}$, being replaced with PBS after each sampling time, followed by HPLC analysis of drug concentration. Experiments were carried out at least in triplicate using different corneas for each repeat. Apparent permeability and steady-state flux were calculated using the following equation:

$$
P_{a p p}=\frac{\Delta Q}{\left(\Delta t \times 60 \times A \times C_{0}\right)}
$$

where $P_{\text {app }}$ is the apparent permeability of timolol maleate across bovine cornea, $Q$ is the total amount permeated at time $t, \Delta Q / \Delta t$ is the steady-state flux into the receiving solution $\left(\mathrm{nmol} \mathrm{min}^{-1}\right)$ and this is equal to the gradient of the linear portion of the graph, 60 is the minutes to seconds conversion rate, $A$ is the area of exposed cornea $\left(1.54 \mathrm{~cm}^{2}\right)$, and $C_{0}$ is the initial amount of drug added to the donor chamber.

\subsection{Synthesis of fluorescent labeled polymers}

FITC-chitosan was synthesized following our previously published protocol (Cook et al., 2011). Both anionic polymers, alginate and hyaluronic acid, were fluorescently labeled using fluoresceinamine (isomer I, Sigma-Aldrich) using a method adapted from Cook et al. (2015). A mass of fluorophore equivalent to react with a $10 \%$ of polymer carboxyl reactive groups $(0.1$ equivalents) was added to a $1 \%(\mathrm{w} / \mathrm{v})$ polymer solution in PBS. Prior to the addition of the 
fluoresceinamine, the carboxyl groups were activated by the addition of EDC ( 0.1 equivalents) and Sulfo-NHS (0.2 equivalents), at $\mathrm{pH}$ 6.0. They were mixed for approximately 15 min prior to dropwise addition of a solution of fluorophore in methanol $(1 \mathrm{~mL})$ and $\mathrm{pH}$ adjustment to 7.0. The reaction was allowed to proceed $24 \mathrm{~h}$ in the dark at room temperature and then dialyzed against $4 \mathrm{~L}$ of deionized water in the dark until fluresceinamine was not present in the dialysate. The resulting product was freeze-dried (Heto Power Dry LL 3000 freeze-drier, Thermo Electron Corporation) and kept wrapped in aluminum foil to avoid exposure to light.

\subsection{Corneal integrity}

The effect of different formulations containing fluorescently-labelled polymers alone or in combination with permeability enhancers on corneal integrity was investigated using the whole eye method (Morrison et al., 2013; Mun et al., 2014). Whole bovine eyes were placed in individual 150 $\mathrm{mL}$ beakers, cornea facing uppermost. A Franz diffusion cell donor compartment was placed on the cornea and held in place using a cling film, ensuring a good seal at the corneal surface; the beakers were placed in a water bath at $37 \pm 1^{\circ} \mathrm{C}$ and allowed to equilibrate for 30 min after which $1 \mathrm{~mL}$ of timolol solutions were added to the donor compartment. Corneas were exposed to the solutions for $120 \mathrm{~min}$ and then sections were cut using a microtome and analysed using fluorescence microscopy, as described above.

\subsection{Polymer retention test}

The retention of polymers on bovine corneas was assessed using a method modified from previous published procedures (Al Khateb et al., 2016; Cave et al., 2012). Extracted cornea was mounted on a glass slide and incubated at $37^{\circ} \mathrm{C}$ for $5 \mathrm{~min}$, and then $200 \mu \mathrm{L}$ sample of fluorescently-labelled polymer or FITC-dextran $\left(1 \mathrm{mg} \mathrm{mL}^{-1}\right)$ was pipetted onto the surface of the cornea, placing the slide into a sloped channel at $37^{\circ} \mathrm{C}$. The tissue was washed by dripping simulated tear fluid (STF: $6.78 \mathrm{~g}$ $\mathrm{L}^{-1} \mathrm{NaCl}, 2.18 \mathrm{~g} \mathrm{~L}^{-1} \mathrm{NaHCO}_{3}, 0.084 \mathrm{~g} \mathrm{~L}^{-1} \mathrm{CaCl}_{2}$, and $1.38 \mathrm{~g} \mathrm{~L}^{-1} \mathrm{KCl}$, adjusted to $\mathrm{pH} 7.4$ with $\mathrm{HCl}$ ) using a syringe pump at a constant flow rate. At pre-defined intervals, fluorescence images of the 
whole tissue were acquired using Leica DFC3000G digital camera attached to a Leica MZ10F stereo-microscope (Leica Microsystems, Germany) fitted with a GFP filter and Leica Application Suit (LAS) software (version 4.4.0). The fluorescence images were analysed using ImageJ (version 1.46r) to measure the total pixel intensity of the images. The background pixel intensity corresponding to an image of the cornea without the polymers was subtracted from each measurement. Fluorescence data was normalised (\%) by dividing the fluorescence recorded at each time by the initial value taken after polymer exposure, and percentage fluorescence was modeled using Equation (4) written below.

\subsection{Mathematical models}

\subsubsection{Drug permeability}

Logistic equations are widely accepted models for the description of drug dissolution kinetics (Zhang et al., 2010). In this case, we used a logistic equation where all parameters had biological meaning and the lag-time after which the permeation of timolol occurred could be directly obtained from the equation as the intersection of the tangent at the inflection point with the abscissa axis (Vázquez and Murado, 2008). The equation is similar to the logistic equation reported in Zhang et al. (2010) as one of the models included in the DDSolver software for the description of drug dissolution profiles, and was taken from Vázquez and Murado (2008):

$$
Q=\frac{Q_{m}}{1+\exp \left(2+\frac{4 \times v_{m} \times(\lambda-t)}{Q_{m}}\right)}
$$

where $Q$ is the total amount of drug permeated at time $t, Q_{\max }$ is the maximum amount of drug permeated, $v_{\mathrm{m}}$ is the maximum rate of drug permeation and equals the steady-state flux $(\Delta Q / \Delta t)$ into the receiving solution $\left(\mathrm{nmol} \mathrm{min}^{-1}\right)$, and $\lambda$ is the lag-time (min) after which the permeation of the drug begins. Fitting procedures and parametric estimations were carried out by minimizing the sum of quadratic differences between observed and model predicted values using the nonlinear leastsquares (quasi-Newton) method provided by the Solver macro of the Microsoft Excel 2011 
spreadsheet for Mac (Microsoft, Redmond, WA, USA). Confidence intervals from the parametric estimates and consistency of mathematical models (Student's $t$ and Fisher's F tests; $\alpha=0.05$ ) were evaluated using the Solver Aid (Prikler, 2009). The $P_{\text {app }}$ was then calculated by substituting the steady-state flux obtained from Equation (3) in Equation (2).

\subsubsection{Polymer retention}

The polymer retention data from fluorescence images quantified via ImageJ and normalized as percentage, were adjusted using the following two-phase decay equation:

$$
\begin{aligned}
F=F_{P}+100 & \times\left[f \times \exp \left(-k_{f} \cdot t\right)+(1-f)\right. \\
\times & \left.\left(-k_{s} \cdot t\right)\right]
\end{aligned}
$$

where $F$ is the remaining fluorescence $(\%)$ after a time $t, F_{\mathrm{P}}$ is the plateau $(\%)$ that represents the remaining fluorescence at infinite $t, f$ is the percentage of polymer that is washed-off faster, $k_{\mathrm{f}}$ is the fast wash-off rate $\left(\mathrm{min}^{-1}\right)$, and $k_{\mathrm{s}}$ is the slow wash-off rate $\left(\mathrm{min}^{-1}\right)$. Plotting, data fitting and parametric estimations (Student's t- test, $\alpha=0.05$ ) were performed using the GraphPad Prism TM5 (GraphPad Software Inc., San Diego, CA, USA).

\section{Results and discussion}

\subsection{Trans-corneal permeability of timolol maleate}

The corneal epithelium constitutes the anterior layer of the eye, being the major barrier to ocular drug permeability. The epithelium lipophilic nature contributes to around $90 \%$ resistance to hydrophilic drugs and 10\% to hydrophobic drugs (Washington et al., 2001; Wilson et al., 2001). Timolol maleate is soluble in water (Aggarwal and Kaur, 2005) and therefore has a low permeability into the cornea, being rapidly cleared due to nasolacrimal drainage. The drug loss leads to a systemic absorption that may cause respiratory and cardiovascular side effects, and hence it is necessary to find alternatives to enhance the ocular bioavailability of timolol maleate (ElKamel, 2002). In this paper, we studied the effect of different biopolymers (hyaluronic acid, 
alginate and chitosan) and permeability enhancers (EGTA and HP-ß-cyclodextrin) on the permeability of timolol maleate. For this purpose, we used fresh bovine cornea preserved in the same conditions as previously published papers on the permeability of riboflavin (Morrison et al., 2013; Morrison and Khutoryanskiy, 2014).
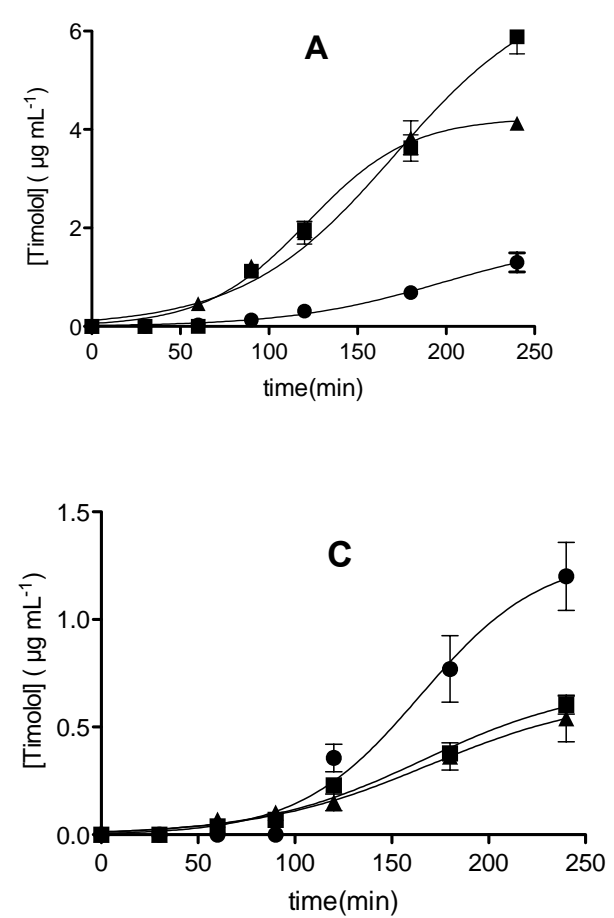
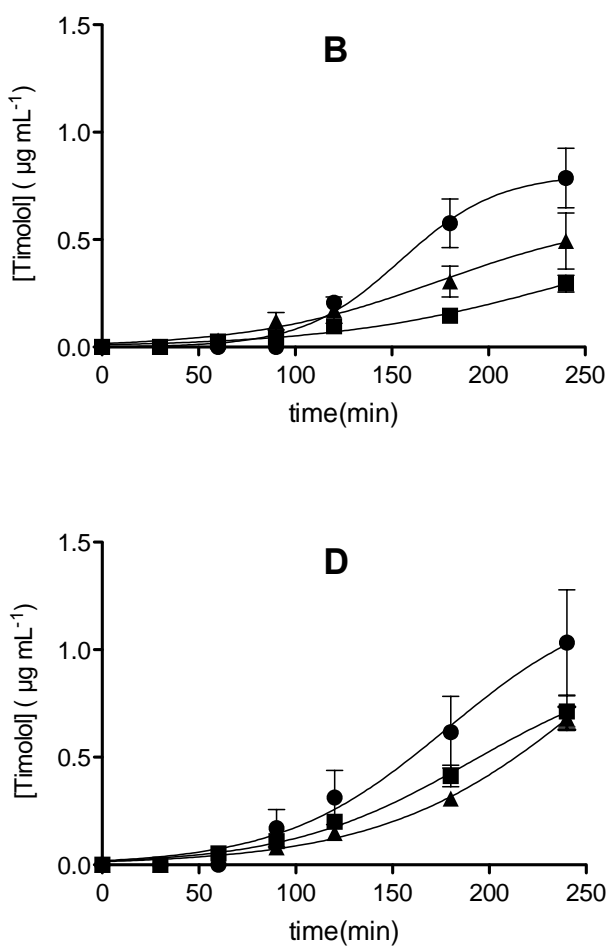

Figure 1. Permeability of timolol maleate $\left(5 \mathrm{mg} \mathrm{mL}^{-1}\right)$ solutions through bovine cornea. Timolol solutions alone $(\boldsymbol{O})$ or in combination with $5 \mathrm{mg} \mathrm{mL}^{-1}$ EGTA $(\boldsymbol{\Delta})$ and $30 \mathrm{mg} \mathrm{mL}^{-1} \mathrm{HP}-\beta-\mathrm{CD}(\boldsymbol{\square})$ were tested. Control series in PBS (A), and formulations containing $1 \mathrm{mg} \mathrm{mL}^{-1}$ hyaluronic acid (B), alginate (C) or chitosan (D) are shown. Error bars correspond to triplicate measurements of drug concentration in the receiving solution of Franz diffusion cells through cornea permeation. Lines represent the fitting of Equation (3) to the experimental data.

The permeation of the drug showed a lag-time of around $90 \mathrm{~min}$ before it was detected in the receiving solution of Franz diffusion cells (Figure 1). In accordance with previous observations, this lag time is a consequence of the diffusion of the drug into the cornea before it can be detected in the receiving solution. As a result of this lag-phase, timolol permeability kinetics showed sigmoidal curves in all cases (Figure 1). The calculation of $P_{a p p}$ usually disregards the initial lag-phase of the 
curve, and the permeability is calculated from the steady-state flux (Equation 2), which is the slope of the linear portion of the curve. Although this is a general procedure for calculating the permeability parameters in drug delivery systems, nonlinear adjustment is a preferred alternative when there is a delay in drug permeation, because it avoids selecting the linear portion of the graph, reducing the subjectivity of the analysis. In this study, the logistic equation utilized (Vázquez and Murado, 2008) adequately described the permeability of timolol maleate through bovine corneas (Fisher's F-test, $\alpha=0.05$ ), and parameter estimations were almost always significant (Student's t-test, $\alpha=0.05)$. Besides, the correlation coefficients between observed and expected values $\left(r^{2}\right)$ were higher than 0.98 , whereas the linear model provided values as low as 0.93 (Table 2). In addition, the use of nonlinear regression has the advantage of explicitly providing the lag-time as a one of the parameters of the equation which, again, avoids a subjective analysis of the permeability kinetics.

The concentration of timolol maleate in additive-free solution recorded after $240 \mathrm{~min}$ of corneal contact was $1.37 \mu \mathrm{g} \mathrm{mL}^{-1}$ (Figure $\left.1 \mathrm{~A}\right)$. The apparent permeability $\left(P_{a p p}\right)$ of timolol through bovine corneas was significantly enhanced in solutions containing EGTA $\left(5 \mathrm{mg} \mathrm{mL}^{-1}\right)$ and HP-ß-CD (30 $\mathrm{mg} \mathrm{mL} \mathrm{m}^{-1}$ ) when compared to timolol in PBS (Table 2), but none of the polymers provided improvement in drug permeation (Figure $1 \mathrm{~B}, \mathrm{C}$ and D). Both EGTA and HP-B-CD increased the $P_{\text {app }}\left(p<0.01\right.$, one-way ANOVA) of timolol to 1.46 and $1.32 \times 10^{-6} \mathrm{~cm} \mathrm{~s}^{-1}$, respectively, compared to the control $\left(0.46 \times 10^{-6} \mathrm{~cm} \mathrm{~s}^{-1}\right)$. Besides, according to nonlinear adjustment, both formulations significantly increased $(p<0.001)$ the maximal amount of drug permeated and the steady-state flux into the receiving solution (Table 2). These results are in agreement with previous reports showing enhanced permeability of riboflavin through bovine cornea in formulations containing calcium sequestering compounds (Morrison and Khutoryanskiy, 2014), and cyclodextrins (Morrison et al., 2013) at the same concentration as those used in the present study. Also, a recent study found a formulation combining $\alpha-\mathrm{CD}$ and EDTA was characterized by a significantly higher permeation of cysteamine across the cornea (Pescina et al., 2016), compared to benzalkonium chloride containing solution. The damage caused by both calcium chelators and cyclodextrins in the ocular surface is 
most likely responsible for the improved permeability of timolol maleate. Actually, cyclodextrins are well-known disruptors of the integrity of the epithelium, increasing the permeability of low molecular weight molecules (Mun et al., 2014), such as timolol maleate (316.4 Da).

The addition of $1 \mathrm{mg} \mathrm{mL}^{-1}$ solutions of hyaluronic acid, alginate or chitosan to timolol formulations reduced drug permeation, lowering the maximal amount of permeated drug, and decreasing the steady-state flux through the cornea (Table 2). The lower timolol permeability was particularly unexpected in solutions containing chitosan, since this cationic polymer is reported to have permeability enhancer properties (Di Colo et al., 2008), as well as the ability to induce reversible opening of tight junctions in epithelial cell models (McEwan et al., 1993; Ranaldi et al., 2002). Hyaluronic acid was also reported to enhance the permeability of acyclovir through buccal, vaginal and intestinal cell models (Sandri et al., 2004), and to enhance drug absorption through the skin due to the increased hydration of the outer layers of the skin (Brown et al., 2005). The addition of polymers to timolol formulations also increased the lag-time ( $\mathrm{p}>0.05$, one-way ANOVA) of drug permeation from $85 \mathrm{~min}$ in $\mathrm{PBS}$ solution to more than $100 \mathrm{~min}$ in formulations containing hyaluronic acid and alginate (Table 2). The prolonged residence of formulations containing some polymers was reported to be due to both the increase in the viscosity of the solutions as well as their mucoadhesivity (Kaur and Smitha, 2002). The increase in the time taken to achieve a measurable drug concentration in the receptor compartment of Franz cells is due to the slower diffusion of the drug into the cornea, which would eventually imply an increase in the residence time of the drug. Despite the pre-corneal prolonged residence time of timolol not being translated into an increased permeability through the cornea, the longer contact time with the eye could be an opportunity for the absorption through other routes. For instance, timolol like other B-blockers, was reported to have better permeability through the conjunctiva (Ashton et al., 1991), and this could be an alternative absorption foute for this compound. 
Table 2. Paremeters of timolol maleate permeability through bovine cornea in the presence of different formulations containing polymers, cyclodextrins and chelating agents. Mean and confidence intervals of linear (Equation (2)) and non-linear (Equation (3)) adjustment of data are shown.

\begin{tabular}{|c|c|c|c|c|c|c|c|c|}
\hline \multirow{2}{*}{ Formulation } & \multicolumn{3}{|c|}{ Linear } & \multicolumn{4}{|c|}{ Non-linear } & \multirow[b]{2}{*}{$\mathrm{R}^{2}$} \\
\hline & $\begin{array}{c}\Delta \mathrm{Q} / \Delta \mathrm{t} \\
\left(\mathrm{nmol} \mathrm{min} \mathrm{m}^{-1}\right)\end{array}$ & $\begin{array}{c}P_{\text {app }} \times 10^{-6} \\
\left(\mathrm{~cm} \mathrm{~s}^{-1}\right)\end{array}$ & $\mathrm{R}^{2}$ & $\begin{array}{c}Q_{m} \\
(\mathrm{nmol})\end{array}$ & $\begin{array}{c}V_{m} \\
\left(\mathrm{nmol} \min ^{-1}\right)\end{array}$ & $\begin{array}{c}\lambda \\
(\min )\end{array}$ & $\begin{array}{c}P_{a p p} \times 10^{6} \\
\left(\mathrm{~cm} \mathrm{~s}^{-1}\right)\end{array}$ & \\
\hline PBS & $0.35 \pm 0.09$ & $0.32 \pm 0.09$ & 0.991 & $81.5 \pm 24.1$ & $0.46 \pm 0.09$ & $85.0 \pm 19.4$ & $0.43 \pm 0.08$ & 0.991 \\
\hline $\mathrm{HA}$ & $0.17 \pm 0.02$ & $0.16 \pm 0.02$ & 0.986 & $39.0 \pm 13.8$ & $0.22 \pm 0.09$ & $108.9 \pm 37.7$ & $0.20 \pm 0.08$ & 0.978 \\
\hline AL & $0.26 \pm 0.01$ & $0.24 \pm 0.01$ & 0.994 & $62.3 \pm 18.8$ & $0.34 \pm 0.11$ & $116.7 \pm 29.9$ & $0.32 \pm 0.10$ & 0.987 \\
\hline $\mathrm{CH}$ & $0.27 \pm 0.01$ & $0.25 \pm 0.01$ & 0.991 & $57.9 \pm 27.1$ & $0.34 \pm 0.11$ & $88.3 \pm 30.5$ & $0.32 \pm 0.10$ & 0.986 \\
\hline EGTA & $1.21 \pm 0.12$ & $1.14 \pm 0.12$ & 0.995 & $266.2 \pm 11.6$ & $1.56 \pm 0.47$ & $85.8 \pm 28.0$ & $1.46 \pm 0.44$ & 0.984 \\
\hline $\mathrm{HA}+\mathrm{EGTA}$ & $0.07 \pm 0.001$ & $0.07 \pm 0.001$ & 0.960 & 40.7 (NS) & 0.17 (NS) & 166.3(NS) & $0.16(\mathrm{NS})$ & 0.989 \\
\hline $\mathrm{AL}+\mathrm{EGTA}$ & $0.13 \pm 0.02$ & $0.12 \pm 0.001$ & 0.975 & $26.6 \pm 10.9$ & $0.16 \pm 0.05$ & $82.7 \pm 29.2$ & $0.15 \pm 0.05$ & 0.983 \\
\hline $\mathrm{CH}+\mathrm{EGTA}$ & $0.15 \pm 0.04$ & $0.14 \pm 0.04$ & 0.975 & $36.8 \pm 14.2$ & $0.19 \pm 0.03$ & $96.0 \pm 21.1$ & $0.18 \pm 0.03$ & 0.996 \\
\hline HPBCD & $0.83 \pm 0.05$ & $0.77 \pm 0.05$ & 0.930 & $161.8 \pm 15.8$ & $1.41 \pm 0.37$ & $64.5 \pm 13.8$ & $1.32 \pm 0.34$ & 0.995 \\
\hline $\mathrm{HA}+\mathrm{HPBCD}$ & $0.07 \pm 0.01$ & $0.07 \pm 0.01$ & 0.986 & $17.2 \pm 8.3$ & $0.09 \pm 0.03$ & $81.1 \pm 29.4$ & $0.09 \pm 0.02$ & 0.983 \\
\hline$A L+H P B C D$ & $0.12 \pm 0.04$ & $0.11 \pm 0.03$ & 0.986 & $24.8 \pm 6.4$ & $0.14 \pm 0.02$ & $81.4 \pm 17.2$ & $0.13 \pm 0.03$ & 0.994 \\
\hline $\mathrm{CH}+\mathrm{HPBCD}$ & $0.15 \pm 0.02$ & $0.14 \pm 0.02$ & 0.940 & 64.6 (NS) & 0.29 (NS) & $149.8 \pm 37.4$ & 0.27 (NS) & 0.995 \\
\hline
\end{tabular}


The formulations containing mucoadhesive polymers together with EGTA or HP- $\beta$-CD significantly reduced $(p<0.001$, one-way ANOVA) the permeability of timolol compared to the permeability enhancers alone (Table 2). The $P_{\text {app }}$ in ternary (timolol-polymer-enhancer) solutions was reduced from $1.46 \times 10^{-6} \mathrm{~cm} \mathrm{~s}^{-1}$ in polymer-free solution to $0.15 \times 10^{-6}$ and $0.18 \times 10^{-6} \mathrm{~cm} \mathrm{~s}^{-1}$ (Table 2) in alginate and chitosan solutions, respectively. The maximum amount of drug permeated $(p<0.001)$ and the steady-state flux $(p<0.001)$ were also significantly reduced in EGTA and HP- $\beta$ CD polymer-containing solutions. This might be due to the polymeric nature of chitosan, which was reported to reduce the ability of cyclodextrins ( $\beta-\mathrm{CD}$ and HP- $\beta-\mathrm{CD})$ to form complex with drugs bearing different physicochemical properties, being the polymer-cyclodextrin interaction responsible for the reduced drug solubilization observed (Mura et al., 2007). In accordance with this observation, the interactions between cyclodextrin and chitosan, demonstrated by ATR-FTIR studies, were found to reduce the release rate of cyclosporine A from chitosan films intended for ocular application (Jug et al., 2012). Therefore, the reported interaction of HP- $\beta$-cyclodextrin with chitosan, but also of alginate (Burckbuchler et al., 2006) and other polymers (Harada et al., 2014) might explain the unexpected lower timolol permeability observed in ternary systems compared to binary systems (timolol-polymer, Figure 1). 

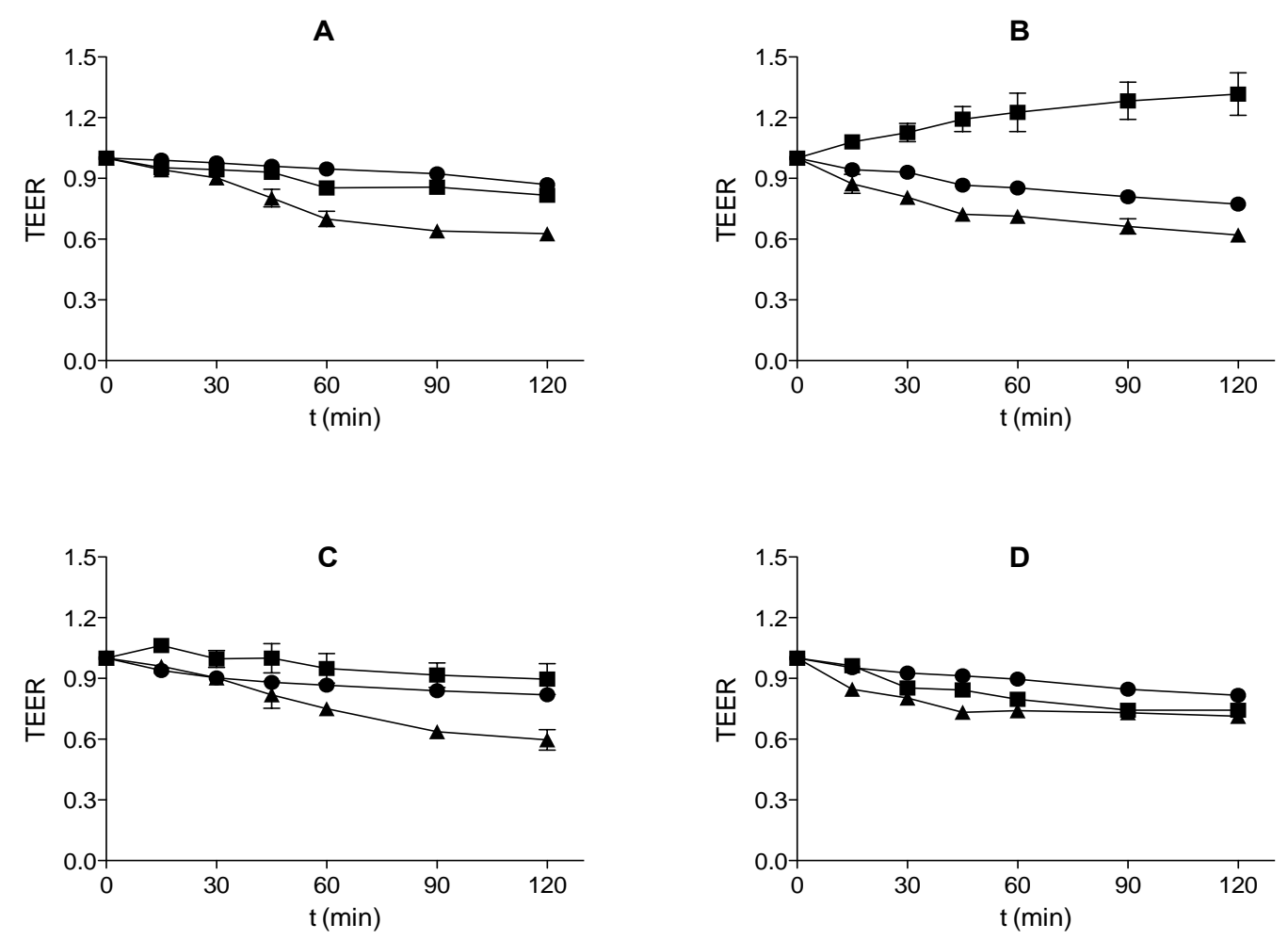

Figure 2. TEER measurements for exposed corneas to: PBS $(\boldsymbol{\bullet}), 5 \mathrm{mg} \mathrm{mL}^{-1} \mathrm{EGTA}(\boldsymbol{\Delta})$ and $30 \mathrm{mg}$ $\mathrm{mL}^{-1} \mathrm{HP}-\beta-\mathrm{CD}(\boldsymbol{\square})$ solutions alone (A) or containing $1 \mathrm{mg} \mathrm{mL}^{-1}$ solutions of hyaluronic acid (B), alginate (C) and chitosan (D). Error bars correspond to triplicate TEER values of exposed bovine cornea through Ussing chambers. Baseline resistance of PBS solution in the experiment cells without a membrane was $0.254 \pm 0.03 \mathrm{k} \Omega$, calculated from the TEER values from Equation (1).

These findings correlate well with the TEER values for HP- $\beta$-CD and hyaluronic acid solution increasing over $120 \mathrm{~min}$, showing a significant increase $(p<0.001$, one-way ANOVA) in final TEER measurements (Figure 2). The increment in TEER value corresponds to a less permeable membrane (Morrison and Khutoryanskiy, 2014), and supports the significantly lower permeability of timolol observed (Table 2). The initial TEER values recorded for bovine corneas were between 2.16 and $2.50 \mathrm{k} \Omega \mathrm{cm}^{2}$ which is in good agreement with previous results (Morrison and Khutoryanskiy, 2014). We observed a reduction of electrical resistance for corneas exposed to PBS from $2.53 \pm 0.03$ to $2.20 \pm 0.10 \mathrm{k} \Omega \mathrm{cm} 2$ over $2 \mathrm{~h}$, representing a $13 \%$ reduction, due to the corneal swelling observed when using in vitro techniques (Morrison and Khutoryanskiy, 2014). 


\subsection{Barrier function of the corneal epithelium}

A further experiment was conducted to test the effect of the solutions containing the polymers alone and with permeability enhancers (HP- $\beta-C D$ or EGTA), on the barrier function of the corneal epithelium. For this purpose fluorescently-labeled polymer solutions were put in contact with whole bovine eyes for $2 \mathrm{~h}$, and then dissected corneas from the whole eye were sectioned and examined using fluorescence microscopy. The whole eye method was developed to study histological changes in the cornea, but avoiding the corneal swelling and the development of structural changes in dissected tissues with time (Morrison and Khutoryanskiy, 2014). Therefore, we followed this methodology because it was shown to reduce potential artifacts occurring when using Franz diffusion cells, and provides experimental in vitro conditions closer to in vivo models (Mun et al., 2014).

Figure 3 compares images of bovine cornea treated with polymers alone or combined with HP- $\beta$ CD or EGTA. Aqueous cyclodextrins (Morrison et al., 2013; Mun et al., 2014) and calcium sequestering compounds (Morrison and Khutoryanskiy, 2014) solutions have shown to disrupt the corneal epithelium integrity by different mechanisms that make the corneal barrier less resistant to drug permeation. This phenomenon was observed to be time-dependent for cyclodextrins, and was evident only after 15 min of corneal exposure (Morrison et al., 2013). However, applying solutions containing any of these permeability enhancers combined with either hyaluronic acid, chitosan or alginate on the corneal surface for $2 \mathrm{~h}$ showed no evidence of epithelial disruption (Figure 3 ). Besides, fluorescence microscopy images of all the treatments tested showed polymer solutions were only observed on the corneal surface, confirming the integrity of the cornea was not disrupted for these large molecules to penetrate. These observations confirm previously reported data where the exposure of the cornea to either FITC-dextran $(4,000 \mathrm{Da})$ or PEG $(5,000 \mathrm{Da})$ did not demonstrate any permeation enhancement of these compounds after $1 \mathrm{~h}$ pre-treatment with $\beta$ cyclodextrin (Mun et al., 2014). These results might suggest epithelial disruption caused by ß- 
cyclodextrins and EGTA is not sufficiently severe for high molecular weight molecules to penetrate.

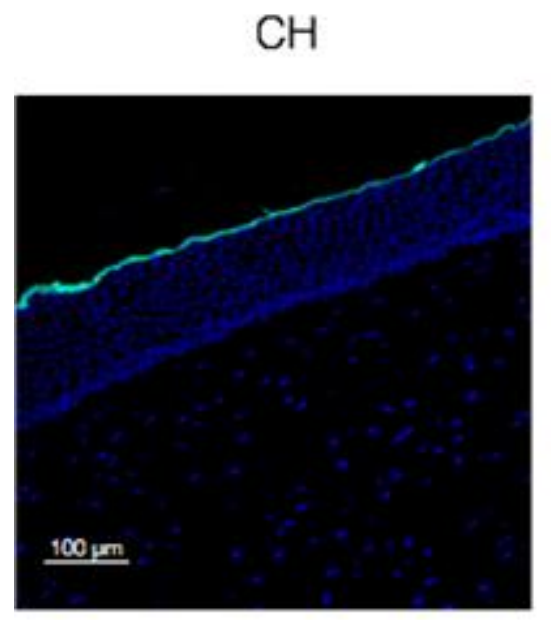

HA

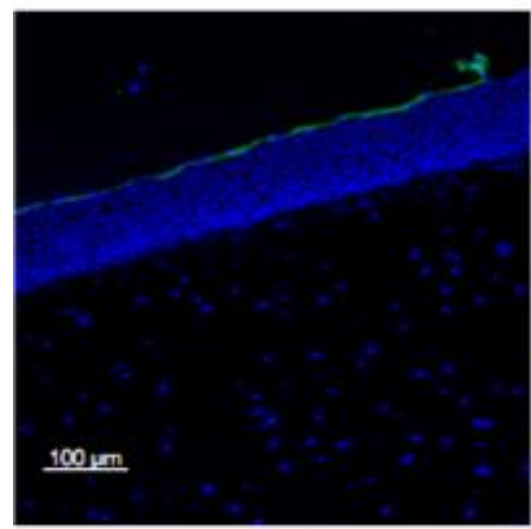

$\mathrm{AL}$

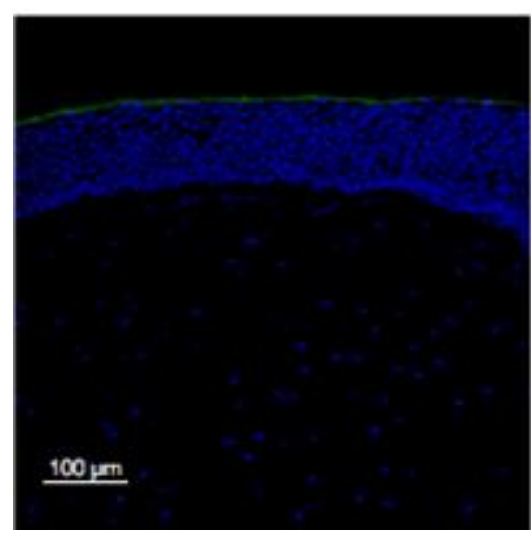

$\mathrm{CH}+\mathrm{EGTA}$

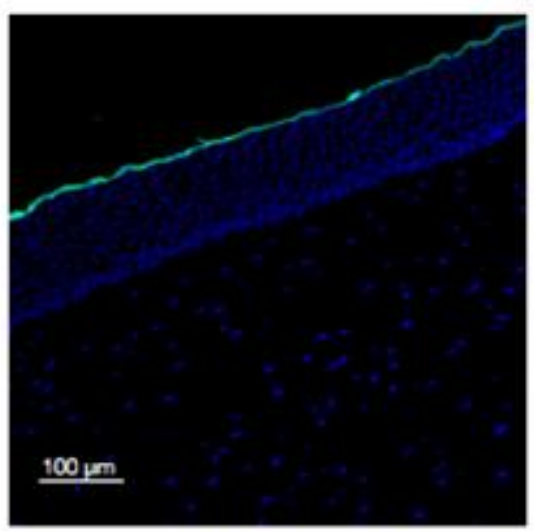

$\mathrm{HA}+\mathrm{EGTA}$

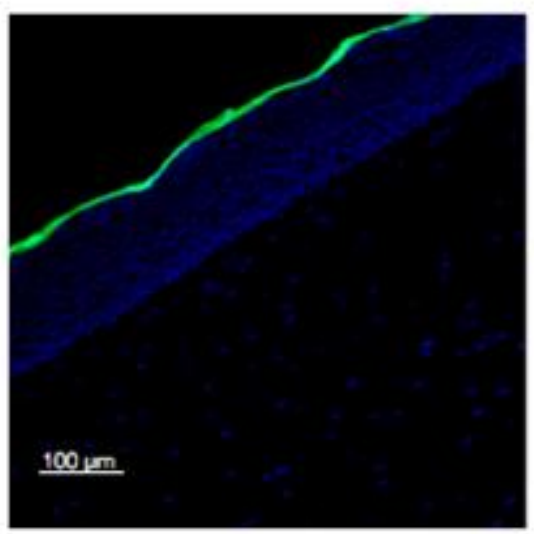

$\mathrm{AL}+\mathrm{EGTA}$

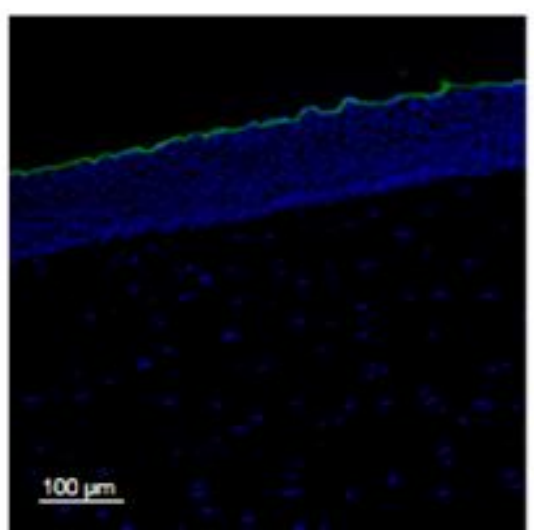

$\mathrm{CH}+\mathrm{HP}-\mathrm{B}-\mathrm{CD}$

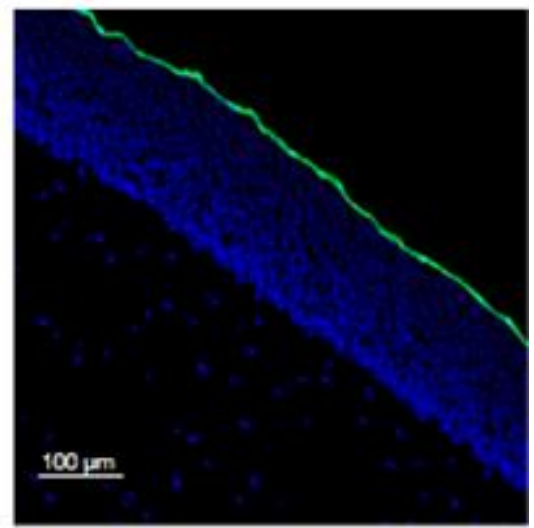

$\mathrm{HA}+\mathrm{HP}-\mathrm{B}-\mathrm{CD}$

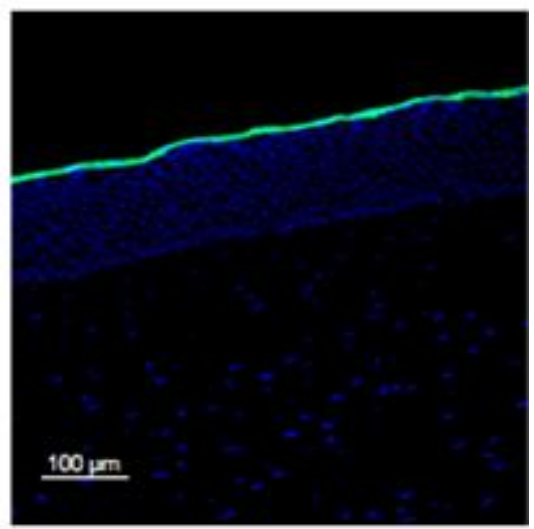

$A L+H P-B-C D$

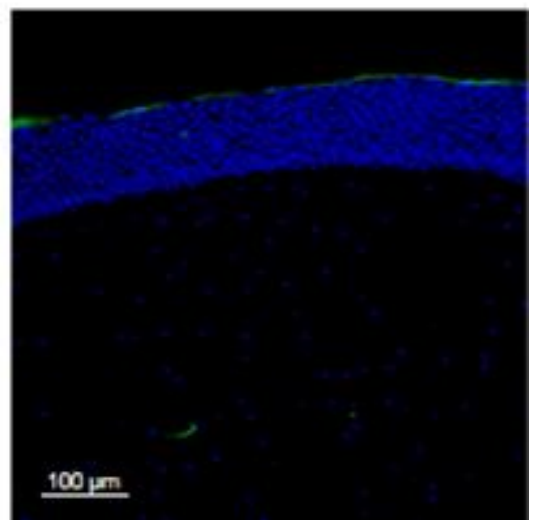

Figure 3. Exemplar fluorescence micrographs of cross section of bovine cornea exposed to formulations containing chitosan (a), hyaluronic acid (b) and alginate (c) alone and in combination with EGTA and HP-ß-CD. Corneas were exposed to the formulations for $2 \mathrm{~h}$ and each experiment was performed in triplicate using different eyes. Size bar: $100 \mu \mathrm{m}$. 
Like other mucosal tissues of the human body, the ocular epithelial cells are coated with mucins which are high-molecular-weight glycoproteins forming a highly hydrated viscoelastic gel layer (Khutoryanskiy, 2010). This film forms a continuous fluid layer over the cornea which acts as a barrier that keeps it moist, protects it from bacterial invasiveness, and prevents foreign bodies from entering into the eye (Mun et al., 2014). The hydrophilic polymers containing charged functional groups such as those utilized in the present study are known to form non-covalent interactions with amino and sialic groups of mucins (Khutoryanskiy, 2010). Recently, new techniques like surface plasmon resonance have provided increased knowledge of the interactions between mucins and adhesive biopolymers, and suggest they may contribute to enhanced retention on apical membranes (Bravo-Osuna, 2012). In agreement with this hypothesis, the polymer-epithelial interactions together with the reduced permeability of timolol maleate observed in vitro, suggest that polymers might constitute an additional barrier towards drug permeation through bovine cornea. The entanglement of polymer chains would form a network reducing drug diffusion, as the higher lagtime of drug permeation in the presence of polymers confirmed (Table 2).

Hyaluronic acid (Ho et al., 2013) and chitosan (Fang et al., 2014) have wound healing properties of the ocular epithelium and are commonly used to treat "dry-eye" syndrome. Indeed, adhesive biopolymers are typically included in ocular drug formulations due to their anti-oxidative properties that counteract epithelial damage caused by preservatives used in ocular formulations (Debbasch et al., 2002). In the same way, we found the addition of permeability enhancers in the presence of polymers had no effect on the corneal integrity (Figure 3). This result suggests the polymerenhancer interaction counteracting the disruptive effect of EGTA or cyclodextrins on the corneal surface. The latter hypothesis is more likely to be responsible for this phenomenon because it also supports the reduced timolol permeability observed in ternary systems compared to binary systems, as explained before. In the same way, previous reports have found reduced drug diffusion and swelling as a result of the formation of a compact matrix due to chitosan-cyclodextrin interactions (Hermans et al., 2014; Jug et al., 2012). 
These findings correlate with the above-discussed results where it was found that polymers reduced timolol maleate permeability upon corneal exposure, whereas the permeability enhancers, when incorporated in the polymers, reduced the permeability significantly more.

\subsection{Mucoadhesive properties of polymers}

In order to compare the mucoadhesive properties of the biopolymers, their retention on ex vivo bovine corneas was assessed according to the methodology described in Al Khateb et al. (2016) (Figure 4). The retention of the fluorescently-labelled polymers on bovine cornea during washing with STF was determined using fluorescence microscopy, and FITC-dextran was used as a nonmucoadhesive polymer (negative control). The exponential decrease in fluorescence after washing was modeled using a two-phase decay equation that considers a first stage of rapid washing of the non-retained polymers, and a second phase when polymers attached to the mucosa are washed slower. The agreement between predicted and experimental data was excellent (Figure 4), with $\mathrm{R}^{2}$ values higher than 0.948 . The $p$-values from Fisher's F -test also indicated Equation (4) consistently described the wash-off data from images, quantified via ImageJ.

The results showed that all polymers ( $\mathrm{p}<0.05$, one-way ANOVA) were retained significantly longer on the corneas than the control, suggesting they all bear certain mucoadhesive properties. According to parametric estimation, the wash-off rate corresponding to the greater retained fraction of polymer $\left(k_{\mathrm{s}}\right)$ was significantly slower for hyaluronan $(p=0.021, t$-test $)$ and chitosan $(p=0.016, t$ test) compared to the control (Figure 4). The retention profiles of chitosan and hyaluronic acid suggest a stable adhesion process with the corneal epithelium, although their different behaviour indicate the nature of these interactions might be different. Chitosan has been reported to bind mucin via ionic interaction between primary amino groups of the glycan and the sialic and sulphonic acid groups of mucins (Bravo-Osuna et al., 2012), together with hydrogen bonding through the interaction of the hydroxyl and amino groups of chitosan (Sogias et al., 2008). On the contrary, it was found that hyaluronic acid needs the development of prior chain inter-diffusion with 
mucin molecules in addition to hydrogen bonding to promote the formation of a sufficiently stable interaction with the ocular epithelium (Bravo-Osuna et al., 2012). 

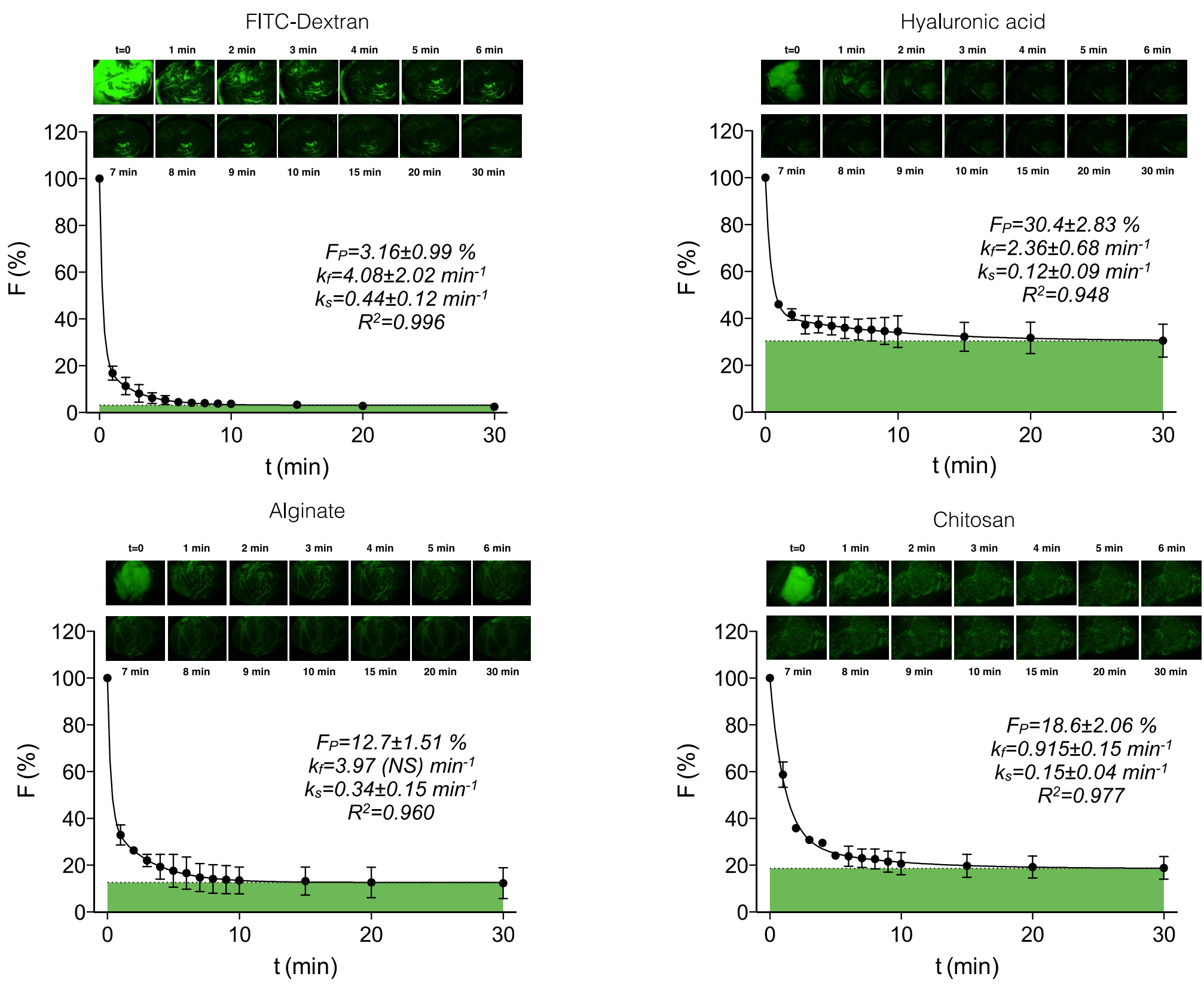
Figure 4. Retention kinetics of fluorescently labelled polymers and FITC-dextran (negative control) on ex vivo bovine cornea. Data (symbols) are the mean of triplicate samples $(n=3)$ and standard deviation (error bars). The lines are the fitting of Equation (4) to experimental data. Parameter estimations (mean and confidence intervals, $\alpha=0.05)$ and correlation coefficients $\left(\mathrm{r}^{2}\right)$ are shown. The green box represents the plateau $\left(F_{P}\right)$ or the remaining fluorescent (\%) after infinite washing. 
This mechanism of interaction could potentially facilitate a better retention of hyaluronic acid on the ocular mucosa compared to chitosan. Indeed, the percentage of hyaluronic acid bound after infinite wash $\left(F_{\mathrm{p}}\right)$ was $30.4 \%$, while a $18.8 \%$ of chitosan and a $12.7 \%$ of alginate remained attached to the corneal epithelium (Figure 4). The more stable interaction of hyaluronic acid was then reflected in a significantly higher retention than chitosan $(p=0.027, t$-test $)$ and alginate $(p=0.005)$. The poorer mucoadhesive properties of alginate is in accordance with previous reports showing this polymer exhibits weaker interactions with mucins compared to other biopolymers, such as chitosan (Haugstad et al., 2015).

Interestingly, the differences in mucoadhesion correlated well with the observed permeability of timolol maleate through bovine cornea; in such a way that, the higher the mucoadhesivity of the polymer, the lower the permeability of the drug through the cornea (Table 2). Nevertheless, longer corneal retention may enhance bioavailability by other routes of absorption in addition to the corneal pathway.

\section{Conclusions}

The addition of permeability enhancers (EGTA and HP-ß-CD) improved the permeation of timolol maleate through bovine cornea, in accordance with previous reports. However, timolol formulations containing bioadhesive polymers (hyaluronic acid, chitosan, alginate) alone or together with both permeability enhancers were found to lower drug permeation. Fluorescence microscopy analysis of the epithelium surface did not establish any evidence of epithelial disruption after $2 \mathrm{~h}$ of treatment with EGTA or HP-ß-CD combined with the polymers, suggesting that the polymer-enhancer interactions reduce drug solubilization and counteract the disruptive effect of the permeability enhancers on the surface of the cornea. Besides, the fluorescently-labelled polymers were only observed on the surface of the cornea, confirming that there was no sufficient disruption of the epithelium for the biopolymers to penetrate. 
On the other hand, mucoadhesive studies revealed a stable interaction of chitosan and hyaluronic acid with the epithelium, while alginate showed poor mucoadhesive properties. The different retention profiles of chitosan and hyaluronic acid suggest the nature of the interaction with mucins is different. This is in agreement with previous research indicating chitosan-mucin interactions are predominantly due to electrostatic attraction and hydrogen bonding, while hyaluronan-mucin stable interaction needs the development of chain-interdiffusion in addition to other non-covalent bonding. The differences in mucoadhesion correlated with the permeability of timolol maleate observed, i.e. formulations containing greater quantities of mucoadhesive polymers showed lower drug permeabilities.

\section{Acknowledgements}

Isabel Rodríguez was funded by a postdoctoral contract from the Xunta de Galicia, Spain (Plan I2C, 2012). We also thank the Leverhulme Trust for funding the in vitro ocular retention experiments in this study (RPG-2013-017). We thank Dr. Peter Morrison, Dr. Ellina Mun, and Chris J. Humphrey for providing useful advice on this work. We are also grateful to P. C. Turners, Abattoirs (Farnborough, United Kingdom), for the supply of the bovine eyes.

\section{Bibliography}

Aggarwal, D., Kaur, I.P., 2005. Improved pharmacodynamics of timolol maleate from a mucoadhesive niosomal ophthalmic drug delivery system. Int. J. Pharm. 290, 155-159.

Al Khateb, K., Ozhmukhametova, E.K., Mussin, M.N., Seilkhanov, S.K., Rakhypbekov, T. K., Lau, W.M., Khutoryanskiy, V.V., 2016. In situ gelling systems based on pluronic F127/pluronic F68 formulations for ocular drug delivery. Int. J. Pharm. 502, 70-79.

Almeida, H., Amaral, M.H., Lobão, P., Lobo, J.M.S., 2014. In situ gelling systems: A strategy to improve the bioavailability of ophthalmic pharmaceutical formulations. Drug Discov. Today 19, $400-412$. 
Amado, I.R., Vázquez, J.A., Pastrana, L., Teixeira, J.A., 2016. Cheese whey: a cost-effective alternative for hyaluronic acid production by Streptococcus zooepidemicus. Food Chem. 198, 5461.

Andrés-Guerrero, V., Vicario-de-la-Torre, M., Molina-Martínez, I.T., Benítez-del-Castillo, J. M., García-Feijoo, J., Herrero-Vanrell, R., 2011. Comparison of the in vitro tolerance and in vivo efficacy of traditional timolol maleate eye drops versus new formulations with bioadhesive polymers. Invest. Ophthalmol. Vis. Sci. 52, 3548-3556.

Ashton, P., Podder, S.K., Lee, V.H.L., 1991. Formulation influence on conjunctival penetration of four beta blockers in the pigmented rabbit: a comparison with corneal penetration. Pharm. Res. 08, $1166-1174$.

Baudouin, C., 1996. Side effects of antiglaucomatous drugs on the ocular surface. Curr. Opin. Ophthalmol. 7, 80-86.

Bell, N.P., Ramos, J.L., Feldman, R.M., 2010. Safety, tolerability, and efficacy of fixed combination therapy with dorzolamide hydrochloride $2 \%$ and timolol maleate $0.5 \%$ in glaucoma and ocular hypertension. Clin. Ophthalmol. 4, 1331-1346.

Bravo-Osuna, I., Noiray, M., Briand, E., Woodward, A.M., Argüeso, P., Molina Martínez, I. T., Herrero-Vanrell, R., Ponchel, G., 2012. Interfacial interaction between transmembrane ocular mucins and adhesive polymers and dendrimers analyzed by surface plasmon resonance. Pharm. Res. 29, 2329-2340.

Brooks, A.M., Gillies, W.E., 1992. Ocular beta-blockers in glaucoma management. Clinical pharmacological aspects. Drugs Aging 2, 208-221.

Brown, M. B., Jones, S.A., 2005. Hyaluronic Acid: a unique topical vehicle for the localized delivery of drugs to the skin. J. Europ. Acad. Dermatol. Venereol. 19, 308-318. 
Burckbuchler, V., Kjøniksen, A.L., Galant, C., Lund, R., Amiel, C., Knudsen, K.D., Nyström, B., 2006. Rheological and structural characterization of the interactions between cyclodextrin compounds and hydrophobically modified alginate. Biomacromol. 7, 1871-1878.

Cave, R.A., Cook, J.P., Connon, C.J., Khutoryanskiy, V.V., 2012. A flow system for the on-line quantitative measurement of the retention of dosage forms on biological surfaces using spectroscopy and image analysis. Int. J. Pharm. 428, 96-102.

Cook, M.T., Tzortzis, G., Charalampopoulos, D., Khutoryanskiy, V.V., 2011. Production and evaluation of dry alginate-chitosan microcapsules as an enteric delivery vehicle for probiotic bacteria. Biomacromol. 12, 2834-2840.

Cook, M.T., Smith, S.L., Khutoryanskiy, V.V., 2015. Novel glycopolymer hydrogels as mucosamimetic materials to reduce animal testing. Chem. Commun. 51, 14447-14450.

Debbasch, C., De La Salle, S.B., Brignole, F., Rat, P., Warnet, J.-M., Baudouin, C., 2002. Cytoprotective effects of hyaluronic acid and carbomer $934 \mathrm{p}$ in ocular surface epithelial cells. Invest. Ophthalmol. Vis. Sci. 43, 3409-3415.

Deli, M.A. 2009. Potential use of tight junction modulators to reversibly open membranous barriers and improve drug delivery. BBA- Biomembranes 1788, 892-910.

Di Colo, G., Zambito, Y., Zaino, C., 2008. Polymeric enhancers of mucosal epithelia permeability: synthesis, transepithelial penetration-enhancing properties, mechanism of action, safety issues. J. Pharm. Sci. 97, 1652-1680.

El-Kamel, A.H., 2002. In vitro and in vivo evaluation of pluronic F127-based ocular delivery system for timolol maleate. Int. J. Pharm. 241, 47-55.

Fang, I.-M., Yang, C.-H., Yang, C.-M., 2014. Chitosan oligosaccharides attenuate ocular inflammation in rats with experimental autoimmune anterior uveitis. Mediat. Inflamm. 2014, 1-15. 
García-López, A., Paczka, J.A., Jiménez-Román, J., Hartleben, C., 2014. Efficacy and tolerability of fixed-combination bimatoprost/timolol versus fixed-combination dorzolamide/brimonidine/timolol in patients with primary open-angle glaucoma or ocular hypertension: A multicenter, prospective, crossover study. BMC Ophthalmol. 14, 262.

Harada, A., Takashima, Y., Nakahata, M. 2014. Supramolecular polymeric materials via cyclodextrin-guest interactions. Acc. Chem. Res. 47, 2128-2140.

Haugstad, K., Håti, A., Nordgård, C., Adl, P., Maurstad, G., Sletmoen, M., Draget, K., Dias, R., Stokke, B., 2015. Direct determination of chitosan-mucin interactions using a single-molecule strategy: comparison to alginate-mucin interactions. Polymers 7, 161-185.

Hermans, K., Van den Plas, D., Kerimova, S., Carleer, R., Adriaensens, P., Weyenberg, W., Ludwig, A., 2014. Development and characterization of mucoadhesive chitosan films for ophthalmic delivery of cyclosporine A. Int. J. Pharm. 472, 10-19.

Ho, W.-T., Chiang, T.-H., Chang, S.-W., Chen, Y.-H., Hu, F.-R., Wang, I.-J., 2013. Enhanced corneal wound healing with hyaluronic acid and high-potassium artificial tears. Clin. Exp. Opt. 96, $536-541$.

Jug, M., Maestrelli, F., Mura, P., 2012. Native and polymeric $\beta$-cyclodextrins in performance improvement of chitosan films aimed for buccal delivery of poorly soluble drugs. J. Incl. Phenom. Macrocycl. Chem. 74, 87-97.

Kaur, I.P., Smitha, R., 2002. Penetration enhancers and ocular bioadhesives: two new avenues for ophthalmic drug delivery. Drug Dev. Ind. Pharm. 28, 353-369.

Khutoryanskiy, V.V., 2010. Advances in mucoadhesion and mucoadhesive polymers. Macromol. Biosci. 11, 748-764. 
Lee, V.H., Robinson, J.R., 1986. Topical ocular drug delivery: recent developments and future challenges. J. Ocul. Pharmacol. 2, 67-108.

Loftsson, T., Stefánsson, E., 2002. Cyclodextrins in eye drop formulations: enhanced topical delivery of corticosteroids to the eye. Acta Ophthalmol. Scand. 80, 144-150.

Lorenz, K., Pfeiffer, N., 2014. Efficacy and safety of tafluprost $0.0015 \%$ and timolol maleate $0.5 \%$ fixed combination in patients with ocular hypertension or open-angle glaucoma. Expert Opin. Pharmacother. 15, 2255-2262.

Ludwig, A., 2005. The Use of mucoadhesive polymers in ocular drug delivery. Adv. Drug Deliv. Rev. 57, 1595-1639.

McEwan, G.T.A., Jepson, M.A., Hirst, B.H., Simmons, N.L., 1993. Polycation-induced enhancement of epithelial paracellular permeability is independent of tight junctional characteristics. BBA - Biomembranes 1148, 51-60.

Morrison, P.W.J., Khutoryanskiy, V.V., 2014. Enhancement in corneal permeability of riboflavin using calcium sequestering compounds. Int. J. Pharm. 472, 56-64.

Morrison, P.W.J., Connon, C.J., Khutoryanskiy, V.V., 2013. Cyclodextrin-mediated enhancement of riboflavin solubility and corneal permeability. Molec. Pharm. 10, 756-762.

Mun, E.A., Morrison, P.W.J., Williams, A.C., Khutoryanskiy, V.V., 2014. On the barrier properties of the cornea: a microscopy study of the penetration of fluorescently labeled nanoparticles, polymers, and sodium fluorescein. Mol. Pharm. 11, 3556-3564.

Mura, P., Corti, G., Maestrelli, F., Cirri, M., 2007. The influence of chitosan on cyclodextrin complexing and solubilizing abilities towards drugs. J. Incl. Phenom. Macrocycl. Chem. 59, 307313. 
Pescina, S., Carra, F., Padula, C., Santi, P., Nicoli, S., 2016. Effect of pH and penetration enhancers on cysteamine stability and trans-corneal transport. Euro. J. Pharm. Biopharm. 107, 171-179.

Prikler, S., 2009. Robert de Levie: Advanced Excel for scientific data analysis, second ed. Anal. Bioanal. Chem. 395, 1945-1946.

Ranaldi, G., Marigliano, I., Vespignani, I., Perozzi, G., Sambuy, Y., 2002. The Effect of chitosan and other polycations on tight junction permeability in the human intestinal Caco-2 cell line. J. Nutr. Biochem. 13, 157-167.

Saettone, M.F., Giannaccini, B., Teneggi, A., Savigni, P., Tellini, N., 1982. Vehicle Effects on ophthalmic bioavailability: the influence of different polymers on the activity of pilocarpine in rabbit and man. J. Pharm. Pharmacol. 34, 464-466.

Sandri, G., Rossi, S., Ferrari, F., Bonferoni, M. C., Zerrouk, N., Caramella, C., 2004. Mucoadhesive and penetration enhancement properties of three grades of hyaluronic acid using porcine buccal and vaginal tissue, Caco-2 cell lines, and Rat Jejunum. J. Pharm. Pharmacol. 56, 1083-1090.

Shell, J.W., 1982. Pharmacokinetics of topically applied ophthalmic drugs. Surv. Ophthalmol. 26, $207-218$.

Sogias, I.A., Williams, A.C., Khutoryanskiy, V.V., 2008. Why Is Chitosan Mucoadhesive? Biomacromol. 9, 1837-1842.

Vázquez, J.A., Murado, M.A., 2008. Mathematical tools for objective comparison of microbial cultures. Biochem. Eng. J. 39, 276-287.

Washington, N., Washington, C., Wilson, C.G., 2001. Ocular drug delivery, in: Physiological Pharmaceutics Barriers to Drug Absorption, second ed. Taylor and Francis, CRC Press, Florida, pp. $249-269$. 
Wilson, C.G., Zhu, Y.P., Kumala, P., Rao, L.S., Dhillon, B., 2001. Ophthalmic drug delivery, in: Hillery, A.M., Lloyd, A.W., Swarbrick, J. (Eds.), Drug delivery and targeting for pharmacists and pharmaceutical scientists. Taylor and Francis, CRC Press, Florida, pp. 329-353.

Zhang, Y., Huo, M., Zhou, J., Zou, A., Li, W., Yao, C., Xie, S. 2010. DDSolver: an add-in program for modeling and comparison of drug dissolution profiles. AAPS J. 12, 263-271. 